\title{
Business Telephone Number
}

National Cancer Institute

\section{Source}

National Cancer Institute. Business Telephone Number. NCI Thesaurus. Code C96961.

The sequence of numbers or characters, that when dialed, connects to a work related telephone. 